\title{
The Role of Culture in Health Literacy and Chronic Disease Screening and Management
}

\author{
Susan J. Shaw $\cdot$ Cristina Huebner · \\ Julie Armin · Kathryn Orzech · James Vivian
}

Published online: 1 May 2008

(C) Springer Science+Business Media, LLC 2008

Erratum to: J Immigrant Minority Health

DOI 10.1007/s10903-008-9135-5

Kathryn Orzech's name was spelled incorrectly as submitted and published online, but is now correct as displayed above. Susan Shaw regrets the error.

The online version of the original article can be found under doi:10.1007/s10903-008-9135-5.

S. J. Shaw $(\bowtie) \cdot$ J. Armin $\cdot$ K. Orzech

Department of Anthropology, University of Arizona,

P.O. Box 210030, Tucson, AZ 85721-0030, USA

e-mail: shaws@email.arizona.edu

C. Huebner

Research Department, Caring Health Center, Springfield,

MA, USA

J. Vivian

Department of Psychology, University of Hartford,

Hartford, CT, USA 